\title{
Design of Power Transformer in MTEM Transmitter Power
}

\author{
Xiao-li Wang, Junxia Gao, Jiashen Tian, Yutao Zhang \\ College of Electronic Information and Control Engineering, \\ Beijing University of Technology, \\ Beijing 100124, China
}

\begin{abstract}
Multi-channel high-power electrical prospecting instrument (MTEM) transmitter is developed on the basis of the bipolar switching power's principle.Thedesign ofthe transformer'smain components is critical to the performance of MTEM transmitter system.The dual-input dual-output $60 \mathrm{KW}$ of power transformers was designed afteranalysistheworksprinciple ofbipolar full-bridge power transformer.TheFinite Element Analysis softwareMaxwell builta 3D model of the transformerand analyzed its internal distribution of the electromagnetic field. While the transformerhasbeen designed out to put intousein the MTEM transmitter system, and applied in the relevant fieldexperiment. The simulation and experiment indicated that this transformer is designed reasonablywith small ripple, low loss, low temperature, high efficiency, stability and reliability.
\end{abstract}

Keywords: electrical prospecting; Maxwell; Power transformer; Finite Element Analysis.

\section{INTRODUCTION}

With the exploitation and utilization of energy, theperformance of multi-channel high-power electrical prospecting instrument (MTEM transmitter) has become a key factorfor thedepth of restricting metal mineral resources.As the keycomponent of MTEM transmitter,transformer'sdesignisrelated to the accuracy and performance of the entire transmitter.Taking into account the limitations of rectifiers' overvoltage and overcurrent andthe whole transmitter'svolume and weight,designing a reasonable transformer scheme iscrucial to the development of the entire transmittersystem.

Firstly, this paper analysis the basic principles of the transmitter, using the AP method for transformer's selection and parameter calculation. Then the software of Maxwell build the 3D model oftransformer , simulation results indicate that whenworking on normal, transformerhas not reached saturation, So it verified the reasonableness of transformer's design scheme.Besides dual-input dual-outputdesign of transformer makes the system decreasesemiconductor's requirements for overvoltage and overcurrent, reducingthe difficulty of system developmentgreatly. Now the transformer has been put into the field experimentand achieved a good result.

\section{MTEM TRANSMITTER'S STRUCTURE AND WORKING PRINCIPLE}

Figure 1 shows the maintopologySchematics of MTEM transmitter.Thecore structureisphase-shifted full- bridge bipolar converter. The system is powered by a generator, thenconnectedto a non-controlled rectifier Bridge Converter. The high-frequency convertercontrols the opening of the IGBT turn-offto achieve power transmissionof transformer.Then it is rectified and filtered so thatobtaining a large voltage of $1000 \mathrm{~V}$. Finally the systemtransmitsvoltagethat is ranging from $100 \mathrm{~V}$ to $1000 \mathrm{~V}$ to the earth continually by adjusting the duty cycle ofthe launching bridge, which is equivalenttotransmitdifferent high frequencies currentto the earth, thengets feedback data to analyze geological structure of formation. The system uses a dual-input dualoutput transformer modeland makes primary windings in parallel.The secondary windingsmake in parallel output afterrectified whenit'sworking at low voltage and high current, or making it in series output when it is working athigh voltage and low current.Figurel shows the mode ofseries. So the system requirements for voltage and current values ofrectifier halve than before that greatly reduces transmitter's cost and size, which ensuresthe system operates stably and efficiently ${ }^{[1]}$.

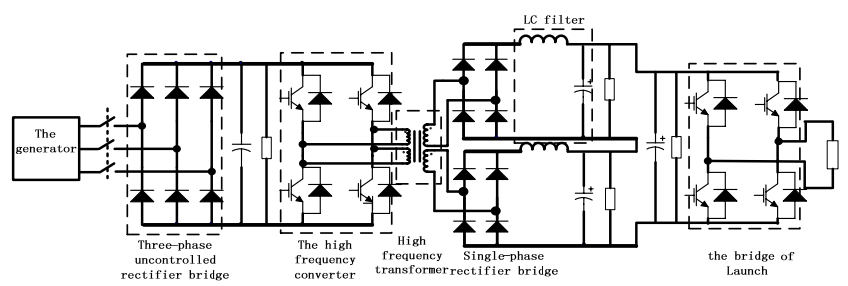

Figure 1. the main topology principle diagramof the MTEM transmitter

\section{III.PARAMETERS' DESIGNATION OF BIPOLAR SWITCHING POWERTRANSFORMER [3]}

\section{A. Selection oftransformer's core material}

The transformer core must have a high Curie temperature and saturation flux, low core loss and residual flux because of the bipolar full-bridge switching power transformers'characteristicsthatarehigh-frequency and high-power.There are many transformer core material types, such aspermalloy, soft magnetic ferrite, amorphous, nanocrystal, etc. At last the system choosesEEtypeManganese-zinc soft magnetic ferritecore whichhaslow loss magnetic, excellent heat dispersing and low eddy current losses. Now Ferrite core technology is already quite maturein china. It has not only a costeffective, but also a stable winding process and stable 
operating performance ${ }^{[3]}{ }^{[4]}$. The parametersare shown in Table 1:

TABLE 1. FERRITE CORE PARAMETERS

\begin{tabular}{|c|c|c|c|c|c|}
\hline $\begin{array}{l}\text { materi } \\
\text { al }\end{array}$ & $\mathbf{s}^{\mathrm{B}}$ & Pfe & $\begin{array}{c}\begin{array}{c}\text { Curie } \\
\text { temperature }\end{array} \\
\end{array}$ & $\begin{array}{l}\text { Perme } \\
\text { ability }\end{array}$ & $\begin{array}{l}\text { Remane } \\
\text { nce }\end{array}$ \\
\hline $\begin{array}{l}\text { Mn- } \\
\text { ZnFerr } \\
\text { ite }\end{array}$ & $\begin{array}{l}0.5 \\
\mathrm{~T}\end{array}$ & $\begin{array}{l}9 \mathrm{~W} / \mathrm{kg} \\
(20 \mathrm{KHZ} ; \mathrm{B}=0.2 \mathrm{~T}\end{array}$ & $215^{\circ} \mathrm{C}$ & 2500 & $0.09 \mathrm{~T}$ \\
\hline
\end{tabular}

B. Parameters calculation step of dual-input dual-output transformer .

In transmitter,the parameters of transformer are designed as follows: Input voltage is $540 \mathrm{~V} \pm 10 \%$ (dual input); output voltage is $729 \mathrm{~V}$ (dual output); Output Current is $50 \mathrm{~A}$; ratio is $1: 1.35$; maximum duty cycle is 0.8 .

The transformer's computationuse $\mathrm{A}_{p}$ method $^{[3]}$ :

$$
\mathrm{A}_{p}=\mathrm{A}_{e} * A_{Q}=\frac{\mathrm{P}_{t} \times 10^{2}}{4 K_{m} f B_{m} j}=518.4 \mathrm{~cm}^{4}
$$

Where $\mathrm{A}_{e}$ is effective cross-sectional area of the core $\left(\mathrm{cm}^{2}\right) ; A_{Q}$ iseffectivewindow areaof core $\left(\mathrm{cm}^{2}\right) ; \mathrm{P}_{t}=$ $116.64 \times 10^{3} \mathrm{~W}$ (transformer apparent power); $K_{m}$ takes 0.25 (thecopper space factor in the core window); $\mathrm{f}=$ $20 \mathrm{KHZ}$ (switching frequency); $B_{m}$ take $250 \mathrm{mT}$ (operating flux density); j take $4.5 \mathrm{~A} / \mathrm{mm}^{2}$ (current density).

Considering the influence of various factors such asswitching devices'transient voltage spikes betweenturn and off in the full-bridge switching power,practical temperature inapplication and others, The value of $A_{p}$ must stay outa certain safety margin when choosing the core.Therefore the selected value of $A_{p}$ isfrom1.5 to3 times larger thanthecalculated value ingeneral ${ }^{[3]}$. The bigger the value of $A_{p}$ is made, the greater the volume and quality of the core is, which will affect the volume and quality of the entire transmitter. While if $A_{p}$ makesa small value that may result transmitters work saturatedeasily. It will affect the performance of thewhole transmitter. At last the systemselectedthe core of EE195after simulatingagain and againwith software of Maxwell. Where $\mathrm{A}_{p}$ is $1212.12 \mathrm{~cm}^{4}, \mathrm{~A}_{e}$ is $16.8 \mathrm{~cm}^{2}, A_{Q}$ is $72.15 \mathrm{~cm}^{2}$

Primary andsecondary winding turns are calculatedas follows:

Primary winding turns $\mathrm{N}_{p 1}$ :

$$
\mathrm{N}_{p 1}=\frac{\mathrm{u}_{P 1} \times T_{\mathrm{on}}}{2 B_{m} A_{e}}=25.7 \approx 26
$$

Secondary winding turnsN $\mathrm{N}_{s 1}$ :

$$
\mathrm{N}_{S 1}=\frac{\mathrm{u}_{P 2}}{\mathrm{u}_{P 1}} \cdot \mathrm{N}_{11}=35.1 \approx 35
$$

Where $\mathrm{u}_{P 1}=540 \mathrm{~V}$ (primary winding voltage); $\mathrm{u}_{P 2}=729 \mathrm{~V}$ (secondary winding voltage); $T_{\text {on }}=20 \mathrm{us}$ (switch conduction time).Taking into account the special situationsthat transformer's secondary windingrequires series whenin the high-voltage and parallel when in the high-current, so that $\mathrm{N}_{P 1}=\mathrm{N}_{P 2}, \mathrm{~N}_{S 1}=\mathrm{N}_{S 2}$.

Primary and secondary coils' diameter:

Primary coils' diameter $d_{1}$ :

$$
d_{1}=1.13 \sqrt{\frac{I_{1}}{j}}=4.139 \mathrm{~mm}
$$

Secondary coils' diameter $d_{2}$ :

$$
d_{2}=1.13 \sqrt{\frac{I_{2}}{j}}=3.562 \mathrm{~mm}
$$

Where $I_{1}=60.37 \mathrm{~A}$ (primary valid current); $I_{2}=$ 44.72A (secondary valid current);As we all know,currents skin effect will increase the effective resistance values of the conductorin the high-frequency and increase system losses. Which willcause transformer heatseriously.The higher the frequencyis, the more significant theskin effect is. While it can be decreased by reducing the diameter'swinding. For example, it can be windingin parallel with multi-strand wiresor litz wires. The smaller the diameter is, the smaller the skin effect is ${ }^{[5]}$. At last insulatedlitz wire is the better choice.

Skin depth:

$$
\Delta=\sqrt{\frac{2}{w u r}} \times 10^{-3}=0.467 \mathrm{~mm}
$$

Where the angular frequency $\mathrm{w}=2 \pi \mathrm{f}$; copper wire permeability $\mathrm{u}=4 \pi \times 10^{-7} \mathrm{H} / \mathrm{m}$; copper wire conductivity $\mathrm{r}=58 \times 10^{-6} \mathrm{~S} / \mathrm{m}{ }^{[7]}$.In the designing ofswitching power, the choice of diameter can't greater than $2 \Delta=0.9346 \mathrm{~mm}$ account to the skin effect. Here it choices $75 \varnothing 0.127(\mathrm{~mm})$ double-insulated litzwire that is suitable the current of $20 \mathrm{kHZ} \sim 50 \mathrm{KHZ}$. The primary coil use 6 sharesrouting in parallel, the secondary coil use 4 sharesrouting in parallel ${ }^{[6]}$.

The producing of transformer's leakage inductance is due to the flux that not only between primary and secondary winding but also between turns and turns isn't coupling completely ${ }^{[3]}$. Usually in order to reduce the leakage inductance of the transformer, it takes primary and secondary winding wound with layered alternately. But to avoid increasing the distributed capacitance ${ }^{[3]}$, the layers can't be too many. The winding's wind manner is shown in figure 3 . In addition, as the primary and secondary voltage of transformer are so large that transformer increased three to four insulating paper between each plus to ensure system's safety. 


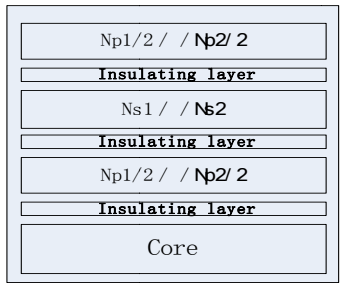

Figure 3. The structure of dual-input dual-output windings

\section{THE 3D SIMULATION OF MAXWELL WITH FINITE ELEMENT ANALYSIS}

In this paper, the finite element analysis software Maxwell build a 3D model of the transformer. Theelectromagnetic field analysissoftware of Maxwell has been widely used in electrical engineering, especially for electromagnetic motor and transformer simulation ${ }^{[8]}$. The software couldanalysis transformer'schange of the internal magnetic field, electric field and magnetic flux density at any time. Whenaddingan external excitationthat is 20KHzsuperimposed wave tothe designed transformer to analogtransmitters' working condition which maximum duty cycle is 0.8 , the simulation results are shown in Figure 4-6.

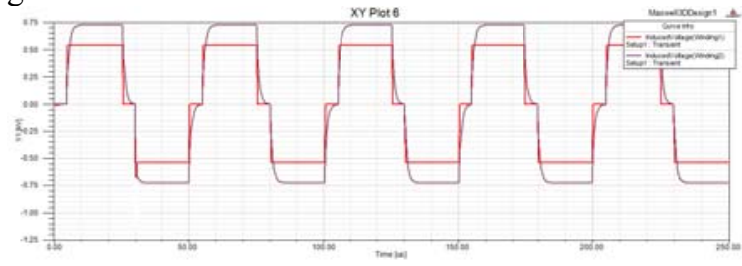

Fig.4. Primary and secondary voltage simulation waveforms of transformer

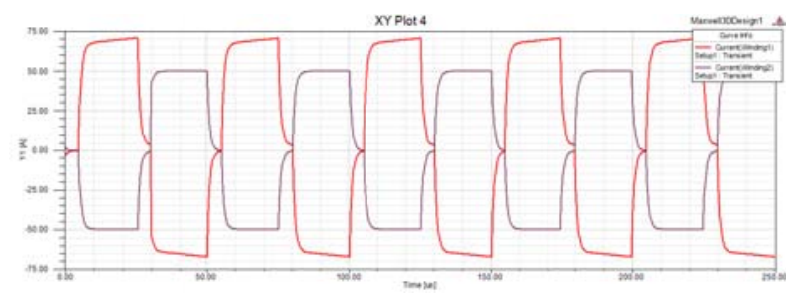

Fig.5. Primary and secondary current simulation waveforms of transformer

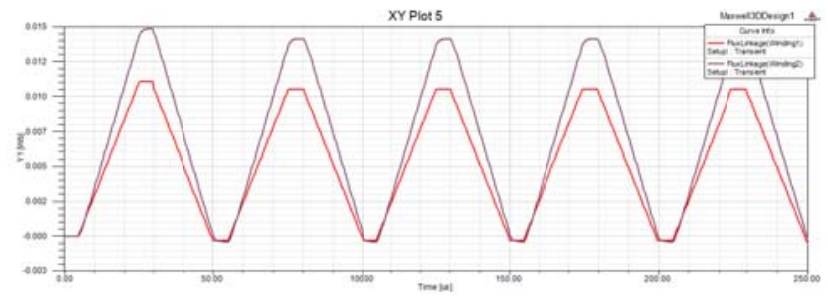

Fig.6. Flux linkage simulation waveforms of transformer

The simulation results in Figure 4-6 indicatethat transformer's input and output voltage, current and fluxlinkage are stablerelatively. Figure7 shows the distribution oftransformer's magnetic flux density and vector,inwhich magnitude and direction of the flux densitycan be seenat every point. When the transformer working at full load, most of the magnetic flux between the $0.1 \mathrm{~T}-0.25 \mathrm{~T}$, only partial point reaches $0.3 \mathrm{~T}$. All of thesimulation results show thattransformerhave a stable output, reached pre-test indicators. And it has not yet reachsaturation at full load which verified the rationality of the designing.

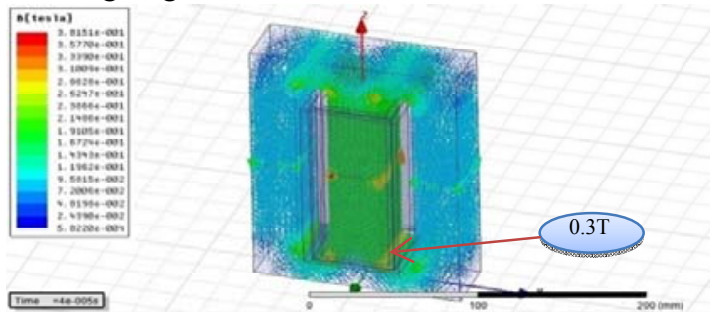

Fig.7. The flux density vector contours oftransformer

\section{PRODUCT AND FIELD EXPERIMENTS}

The designed transformer has beenput into thetransmitter system use, as shown in Figure 8, and it have achieved good results in field experiments. The waveforms of output voltage and current are shown in Figure 9 and the voltage rippleof outputisshown in figure 10.

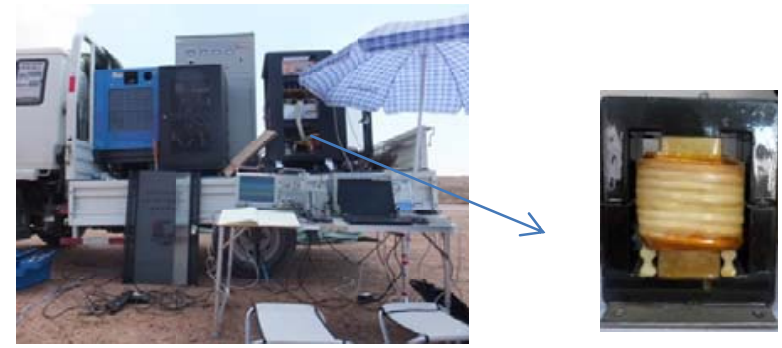

Fig.8. Field experiments of transformer applies in MTEM transmitter system

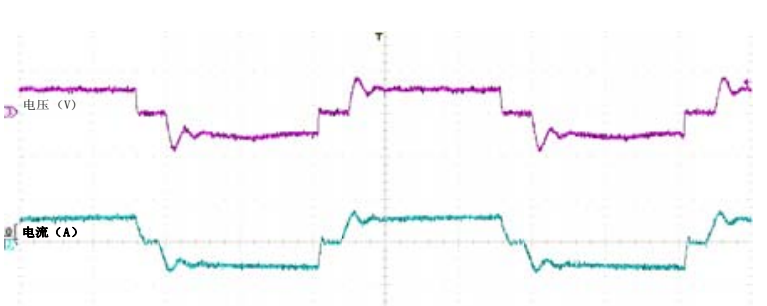

Fig.9. Transformer's output voltage and current waveforms

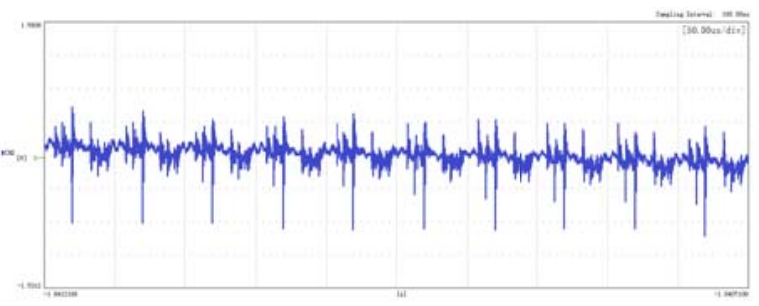

Fig.10. transformer's output voltage ripple waveforms 
Fig. 9 shows thattransformer maintains good output characteristic when the duty cycle is inmaximum. What's morethe transformer has not reached saturationand the output doesn'tproduce a big shock and shake.In addition transformer's temperature is maintained at about $60{ }^{\circ} \mathrm{C}$ which is measured by infrared thermometer. Figure 10 shows the ripple peak is $0.9 \mathrm{~V}(0.12 \%)$. Experiments fully explain that transformer has asmall ripple, a smalltemperature rise anda high efficiency, the design is reasonable which fully meets the requirements of MTEM transmitter's system.Inaddition,transformeradopts dual inputand dual output structure successfully, which not only greatly reduce the difficulty and cost of system's designing, but also reduce the weight and volume of the entire transmitter. All of this laid an important foundationfor the mass production oftransmitters in future.

\section{CONCLUSIONS}

Maxwell simulation and field experiments verify the rationality of the design method. Dualinput and dual output transformer's characteristics are thatleakage inductance small, output stability and temperature riselow, which solved theproblem thatthe excessive demands of entire transmitter system to rectifier pieces. It alsoreduces the size and weight of the entire transmitter system,enhancing the overall performance of the transmitter.All of this laid a solid foundation for the applying of transmitters inexploration industryin future.

\section{REFERENCES}

[1] Abraham 1. Pressman, Keith Billings\&Taylor Morey. Switching Power SupplyDesign[M].McGraw-Hill ProfessionalPublishing,2008.

[2] Keith Billings \&Taylor Morey .Switchmode Power Supply Handbook 3/E[M].McGraw-Hill ProfessionalPublishing,2010

[3] Wang Quan-Bao,New electronic transformers handbook[M].Liaoning Science and Technology ProfessionalPublishing, 2007

[4] Colonel WmT. McLyman .Transformer and Inductor Design Handbook[M], CRC Press Inc,2011

[5] Zhao Xiu-Ke. Switching power supply magnetic components[M].Nanjing University of Aeronautics and Astronautics, 2004

[6] Bai Jian-Min Liu Xiao-xi \&Xu Mei.High density magnetic recording with La-Zn substitution of strontium ferrite films[J], Journal of physical,2000

[7] Electronic transformer Professional Committee. Electronic transformers handbook[M],Liaoning Science and Technology ProfessionalPublishing, 1988

[8] Zhao Bo \&Zhang Hong-Liang.Ansoft12 application in engineering of electromagnetic field[M],China Water Conservancy Post Press, 2010 